\title{
Touch Revisited: Observations and Methodological Recommendations
}

\author{
Julie Dutton, Ashleigh Johnson and Mark Hickson*
}

Department of Communication Studies, UAB College of Arts and Sciences, USA

\begin{abstract}
The authors studied the original source of a study undertaken decades earlier to determine its accuracy as well as the reporting of the study in textbooks. They found that the study had been exaggerated significantly. They revisited the touch study known as the "coffee house" study originally undertaken by Sidney Jourard. The present authors studied cafes in four different states with quite different results from Jourard.
\end{abstract}

\section{Keywords: Communication; Electronic; Learning; People}

\section{Introduction}

In almost any area of interpersonal communication, there are classic studies that virtually any student knows because the studies are cited repeatedly in textbooks as well as in other articles on the subject. Schneider [1] investigated the readability of communication textbooks in basic interpersonal and public speaking courses. In addition to readability of texts, these basic courses have been evaluated in terms of a variety of issues including the reliability of findings. In today's world, textbooks come from a variety of places such as electronic, but within a specific area of communication the contents rarely differ from traditional printed texts. Regardless of what is utilized as the primary text, it should be useful to "double check" its applicability in today's world. Repeating studies that are decades old are a beneficial learning tool for students. In this study, the authors investigate one of these classical studies.

The present authors were interested in updating studies in nonverbal communication text books. As an example of how students can use the updating process to better understand what previous researchers concluded, the authors examined a particular touch study [2]. Two studies on touch were undertaken by Sidney Jourard, a well-known psychologist at the University of Florida, concerning the concept of body accessibility $[3,4]$. These studies are referenced in virtually every nonverbal communication textbook $[5,6]$ as well as advanced readers [7] and some popular books as well [8].

In the primary study on body accessibility, Jourard had participants complete a pencil-and-paper questionnaire about which parts of their bodies the participants would allow opposite-sex friends, same-sex friends, their mothers, and their fathers to touch. It was a self-report based on each individual's conjecture. The study was replicated by researchers a decade later. Over the ten-year separation period between studies, the Rosenfeld group generally found increased accessibility. Once again, Jones and Yarbrough [9], nine years after the second study and 19 years after the first study, replicated Jourard's study. Their procedures were significantly different because the participants themselves transported a touch observation form, in which they selfreported their own touching behavior based on 24 (front and back) body parts. All of those studies were significant because the relatively minor replications improved the studies. As well the researchers demonstrated changes in touching behavior over two decades.

The other portion of Jourard's investigation was a report on the amount of touch between dyads at coffee houses in four different locations: Gainesville, Florida, London, Paris, and San Juan, Puerto Rico. Perhaps strangely, this part of the study (Jourard, 1966) has never been replicated. The "coffee shop" study has been cited at least
444 times, according to Google Scholar. Richmond, McCroskey, and Hickson [10] stated: "A study by Jourard [3] found that the rates of touch per hour among adults in several cultures differed significantly" (p. 187). The variation was from 0 (in London) to 180 (in San Juan) seems unbelievable. The Gainesville report was for 2, and Paris was 120 touches per hour. Frankly, though, Jourard never claimed any intercultural difference that is implied in several textbooks. When teachers discuss the study in class, students are frequently amazed in the number of touches between couples in London, where Jourard reported participants did not touch one another at all and those in San Juan, where Jourard recorded touching one another 180 times an hour. Students in today's classes ask about where exactly in these cities were the coffee houses located? In San Juan, how did Jourard measure three touches per minute? What constituted a touch? Were there any controls in the study? Was the study undertaken in tourist sections of the cities?

In many cases, the Jourard coffee house study is cited as a rationale for intercultural communication differences in tactile behavior. Primarily because of those unanswerable student questions about the study, the researchers went to the original source [4]. "Illustration of such differences is provided by some observations I made during pilot stages of the present investigation. I watched pairs of people engaged in conversation in coffee shops in San Juan (Puerto Rico), London, Paris, and Gainesville, Florida, counting the number of times that one person touched another at one table during a one-hour sitting. The 'scores' were, for San Juan, 180; for Paris, 110; for London, 0; and for Gainesville, 2"' (p.137). This quote is all that Jourard wrote about the coffee houses.

Interestingly, Jourard said he observed "pairs of people" although they are frequently referred to as opposite-sex couples in textbooks. Textbook authors, too, either state or imply that Jourard's coffee shop study was a study in intercultural communication, although it is apparent from the quotation that he did not. Jourard "watched them"

*Corresponding author: Mark Hickson, Department of Communication Studies UAB College of Arts and Sciences, USA, Tel: 205-934-8915; E-mail: hickson@uab.edu

Received August 03, 2017; Accepted September 20, 2017; Published September 25, 2017

Citation: Dutton J, Johnson A, Hickson M (2017) Touch Revisited: Observations and Methodological Recommendations. J Mass Communicat Journalism 7: 348. doi: 10.4172/2165-7912.1000348

Copyright: $\odot 2017$ Dutton J, et al. This is an open-access article distributed under the terms of the Creative Commons Attribution License, which permits unrestricted use, distribution, and reproduction in any medium, provided the original author and source are credited. 
and gave them scores, apparently based on one dyad in each city. To be fair, he indicated that it was in a pilot stage.

While the intent of the study has been distorted by those who quote it, the idea remains an interesting one. To re-test the study, using a pilot methodology, but a systematic methodology, the current authors tested the study using two sub-cultures in the United States. As such the investigators asked two questions.

Research Question 1: Does geographic location affect touch behavior in a rural versus urban environment in the United States?

Research Question 2: Do the results within the United States agree or disagree with those found by Jourard?

\section{Method}

The observers used charts to indicate how many touches occurred during the study. The chart showed pictures of a male and a female, showing 14 body parts. Without sub-dividing the areas of the body into front and back, the researchers drew arrows to indicate each touch, showing who initiated the touch as well as the receiver, and where (what body part) the initiation began as well as where on the body the receiver was touched. As well they noted whether the touch was front or back.

\section{Sampling}

The researchers observed couples in three rural towns and three urban cities. For this study, urban was defined as a town with more than 50,000 residents which is what the US, Census Bureau defines as urban as well. Southeastern cities were utilized as convenience samples. For the rural towns, the places with less than 30,000 people and for urban, more than 200,000. Because all were in the southern region, the cultures were considered the similar, although because they were rural and urban, the sub-cultures were predicted to be different. Those places sampled were from four states in the southeastern United States. Samples were drawn from Georgia, Alabama, Tennessee, and Mississippi. The specific locations were not in places that encouraged substantial tourism. The researchers observed three random couples at each location.

\section{The "Touch" Variable}

Given that Jourard reported 180 touches an hour, the researchers felt that ("number of touches") was virtually impossible to gauge. For example, how could one determine when a touch "stopped" and when another "started"? Therefore, instead of counting numbers of touches, the researchers observed how many minutes [or seconds] the participants touched one another during the study.

Researchers observed the couples in each city for a minimum of 20 minutes per couple. The participants were male and female couples who were either dating or married. In addition, in accordance with the work of Jones and Yarbrough [9], this study observed who initiated the touch and which body parts were touched. In Henley's [11] an observation, her claim was that males significantly initiate touch more frequently in a business context (Table 1).

\section{Results}

There were only two couples who did not touch one another at all, and there were two couples who touched one another only once. Those were the numbers close to those originally reported from London and Gainesville. However, that was only four touches out of a total of 18 couples. In Table 1 (below), are the totals for all touches including the initiator of the touch, the recipient of the touch, the median time for the touch, and the most common parts of the body that were touched.

For Research Question 1, there were more touches (43) in urban situations than in towns (19). Sixty-three (63\%) percent were initiated by males in the towns, and sixty-nine (69\%) percent by males in cities. The parts of the body touched were the same. The length of the touches was longer in cities than in towns. The results indicate that any differences were relatively minor.

For Research Question 2, how these results compare with Jourard we have the following. For the 18 couples, there an average of three touches every 20 minutes. If we extrapolate to Jourard's one-hour time frame, that would mean about nine touches per hour. Even given the three reported touches, the number is higher than what Jourard reported in Gainesville. Of course, the numbers are nowhere near as high as those Jourard reported in San Juan and Paris. With a median of 45 seconds, this study would indicate the numbers reported by Jourard in Paris and San Juan would be unusual if not impossible.

\section{Discussion}

One of the most important findings here is that we should not take the results of studies reported in textbooks, even in most textbooks, as the be all and end all. Jourard was merely mentioning an observation that he had made. To expand the importance of such statements tends to create incorrect information that is carried on for years, if not decades.

To completely replicate Jourard's "pilot study" observations would need to be made in other cities outside the United States. While most common sense observations would indicate that participants in some cultures touch more than in others, more specific data need to be collected. To validate this study, it would be helpful if researchers undertook these observations in other parts of the United States as well.

Should a researcher wish to claim intercultural differences, a variety of coffee houses or restaurants should be investigated. They should be local shops that cater to few tourists; otherwise the results are likely to be distorted.

With all of these observations, it would be beneficial to have two or three observers for each of the dyads studied. Analyzing studies that are frequently reported is a good process for other studies as well.

Textbook authors should make adjustments. Teachers should encourage their students to re-test in cases where results appear unusual. Even if the students find that the study was accurate, it is an excellent exercise for learning.

\begin{tabular}{|c|c|c|c|}
\hline Cities/Towns & Initiator & Recipient & Median time \\
\hline Cities & $23 \mathrm{M}, 10 \mathrm{~F}$ & $23 \mathrm{~F}, 10 \mathrm{M}$ & 1 minute \\
\hline Towns & $12 \mathrm{M}, 7 \mathrm{~F}$ & $12 \mathrm{~F}, 7 \mathrm{M}$ & 25 seconds \\
\hline Totals & $35 \mathrm{M}, 17 \mathrm{~F} \mathrm{(52)}$ & & 45 seconds \\
\hline
\end{tabular}

Table 1: Results of touches. 
Citation: Dutton J, Johnson A, Hickson M (2017) Touch Revisited: Observations and Methodological Recommendations. J Mass Communicat Journalism 7: 348. doi: 10.4172/2165-7912.1000348

Page 3 of 3

\section{References}

1. Schneider DE (1992) A comparison of readability levels of textbooks in public speaking and interpersonal communication. Communication Education 41: 400-404

2. Montagu A (1971) Touching: The human significance of the skin. New York and London: Columbia University Press.

3. Jourard SM (1966) An exploratory study of body accessibility. British Journal of Social and Clinical Psychology 5: 221-231.

4. Jourard SM (1968) Disclosing man to himself. Van Nostrand, Psychology 245.

5. Burgoon JK, Guerrero LK, Floyd K (2010) Nonverbal communication. Boston: Allyn and Bacon.
6. Mehrabian A (2007) Nonverbal communication. New Brunswick, NJ: Aldine Transaction.

7. Hall JA (1984) Nonverbal sex differences: Communication accuracy and expressive style. Baltimore: Johns Hopkins Press.

8. Linden DJ (2015) Touch: The science of hand, heart, and mind. New York: Penguin.

9. Jones SE, Yarbrough AE (1985) A naturalistic study of the meaning of touch Communication Monographs 52: 19-56.

10. Richmond VP, McCroskey JC, Hickson M III (2012) Nonverbal Behavior in Interpersonal Relations, 7th Edition.

11. Henley N (1977) Body politics. Power, sex, and nonverbal communication Prentice Hall 